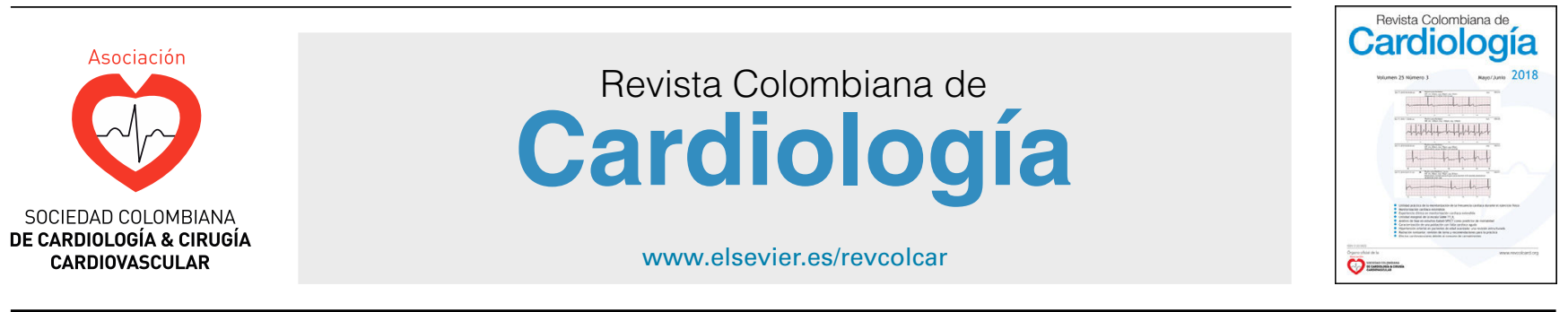

\title{
EDITORIAL
}

\section{A view of advanced heart failure. Is it too late?}

\section{Visión de la insuficiencia cardiaca avanzada ¿Es demasiado tarde?}

\author{
Clara Inés Saldarriaga Giraldo ${ }^{\mathrm{a}, \mathrm{b}, \mathrm{c}}$ \\ a Heart Failure Program, Clínica CardioVID, Medellín, Colombia \\ b Cardiology Program, Universidad Pontificia Bolivariana, Medellín, Colombia \\ c Universidad de Antioquia, Medellín, Colombia
}

Recibido el 23 de agosto de 2019; aceptado el 26 de agosto de 2019

Detecting the point of no return in many diseases faced by clinicians in daily practice is an "art" which is developed based on experience and the frequency with which they treat patients with a particular ailment. Often, when a patient with heart failure is finally referred to a multidisciplinary program after having undergone multiple hospitalizations, and when his/her quality of life and prognosis are seriously jeopardized, several questions arise:

\section{What was done wrong?}

Was there a failure in disease prevention? Were the populationś cardiovascular risk factors inappropriately managed? Was this disease not diagnosed on time? Was there no interest in finding the cause of the impaired ventricular function to try to correct it, and, often, were the pharmacological

\footnotetext{
Véase contenido relacionado en DOI:

https://doi.org/10.1016/j.rccar.2019.09.001

Correo electrónico: clarais@une.net.co
}

and non-pharmacological treatments proven to modify the clinical course of the disease not offered promptly?

\section{Is it too late?}

The ability to detect the danger probably failed. Fortunately, the meaning of this "fine red line" signaling an unfavorable prognosis has recently been simplified thanks to the publication of consensuses updating the definition of advanced heart failure. These include factors beyond the ejection fraction and functional class, such as recurrent hospitalizations, the use of inotropes, cardiac cachexia, frequent defibrillator shocks, drug intolerance, the need for high doses of diuretics to control edemas, involvement of other organs such as the kidney and liver, and severe diminishment of physical capacity using objective measures such as the cardiopulmonary test or six minute walk. These characteristics may even appear in patients with heart failure with preserved function or who are in functional class II of the New York Heart Association (NYHA) classification. 1,2

It is important to remember that patients with acute heart failure may also have criteria of advanced disease and 
require interventions such as early ventricular support. Therefore, strategies such as code shock and the INTERMACS ${ }^{3}$ classification have been successfully implemented worldwide, allowing early decision-making to avoid irreversible damage to other organs and systems.

\section{What treatment was not considered?}

Treatment alternatives depend on the age, prognosis and comorbidities. ${ }^{4}$ Heart transplantation is the treatment option for patients with advanced heart failure who fulfill the criteria; however, it is a limited resource due to a reduction in the number of donors and an increase in the number of patients on the waiting list. The main problem is the delayed referral of patients, when serious impairment of multiple organs and irreversible pulmonary hypertension contraindicate this option. Ventricular assistance is a reality in Colombia, but there are cost and availability limitations. Palliative care is an excellent option when there are no contraindications to advanced treatment; however, this alternative is largely unknown and is considered as a late option, despite its effectiveness in improving quality of life for the patients and their families. . $^{5,6}$

It is important to bear in mind that the current treatment of the disease has improved life expectancy, and thus the number of patients reaching the advanced stage has increased. This population only represents $1 \%$ of the total; however, due to their frequent hospitalizations, they use a significant amount of resources, accounting for $60 \%$ of care costs. ${ }^{7}$

Society and healthcare systems face great challenges in keeping heart failure patients from continuing to arrive "too late'". The main challenge is providing medical education to improve the ability to promptly identify and refer this population. This will only be possible if health care fragmentation is overcome and efficiency is achieved in the implementation of an integrated pathway which will allow communication between physicians all the way from primary care to specialized care. ${ }^{8}$ Another priority is to train medical personnel to identify patients who would benefit from palliative care, improving their ability to discuss the need to change the treatment goals and optimizing communication skills and their relationship with the patients and their families in order to address end-of-life decisions.
None of these interventions will be possible without the commitment of insurance companies to guarantee patient access to a multidisciplinary follow-up in specialized heart failure programs. This is the best way to make the correct decisions regarding the best therapeutic alternative: being rational as to the usefulness and the indication of interventions at the "right time".

\section{Bibliografía}

1. Fang JC, Ewald GA, Allen LA, Butler J, Westlake Canary CA, Colvin-Adams M, et al. Advanced (stage D) heart failure: a statement from the Heart Failure Society of America Guidelines Committee. J Card Fail. 2015;21:519-34.

2. Crespo-Leiro MG, Metra M, Lund LH, Milicic D, Costanzo MR, Filippatos $\mathrm{G}$, et al. Advanced heart failure: a position statement of the Heart Failure Association of the European Society of Cardiology. Eur J Heart Fail. 2018;20:1505-35.

3. Stevenson LW, Pagani FD, Young JB, Jessup M, Miller L, Kormos RL, Naftel DC, Ulisney K, Desvigne-Nickens P, Kirklin JK. INTERMACS profiles of advanced heart failure: the current picture. J Heart Lung Transplant. 2009;28:535-41.

4. Ponikowski P, Voors AA, Anker SD, Bueno H, Cleland JG, Coats AJ, et al. 2016 ESC Guidelines for the diagnosis and treatment of acute and chronic heart failure: The Task Force for the diagnosis and treatment of acute and chronic heart failure of the European Society of Cardiology (ESC). Developed with the special contribution of the Heart Failure Association (HFA) of the ESC. Eur J Heart Fail. 2016;18:891-975.

5. Rogers JG, Patel CB, Mentz RJ, Granger BB, Steinhauser KE, Fiuzat $\mathrm{M}$, et al. Palliative care in heart failure: the PAL-HF randomized, controlled clinical trial. J Am Coll Cardiol. 2017;70:331-41.

6. O’Donnell AE, Schaefer KG, Stevenson LW, DeVoe K, Walsh K, Mehra MR, Desai AS. Social Worker-Aided Palliative Care Intervention in High-risk Patients With Heart Failure (SWAP-HF): a pilot randomized clinical trial. JAMA Cardiol. 2018;3:516-9.

7. Frieder Braunschweig, Martin R, Cowie, Angelo, Auricchio. What are the costs of heart failure? EP Europace. 2011;13(S2):ii13-7.

8. Torres A, Gómez E. Unidades de falla cardiaca: una propuesta para el sistema de salud colombiano. Rev Col Cardiol. 2016;23(S1):13-9.

9. Saldarriaga C, Garcés J, Agudelo A, Guarín L, Mejía J. Impacto clínico del programa de la falla cardiaca en un centro de referencia cardiovascular. Revista Colombiana de Cardiología. 2016;23:260-326. 